Please do not remove this page

RMIT

UNIVERSITY

\title{
A layered SAW device based on ZnO/LiTaO3 for liquid media sensing applications
}

Powell, D; Kalantar-Zadeh, Koroush; Ippolito, Samuel; Wlodarski, W

https://researchrepository.rmit.edu.au/esploro/outputs/9921858211701341/filesAndLinks?institution=61RMIT_INST\&index=null

Powell, D., Kalantar-Zadeh, K., Ippolito, S., \& Wlodarski, W. (2002). A layered SAW device based on $\mathrm{ZnO} / \mathrm{LiTaO} 3$ for liquid media sensing applications. Proceedings of IEEE 2002 Ultrasonics Symposium, 493-496. https://doi.org/10.1109/ULTSYM.2002.1193449

Published Version: https://doi.org/10.1109/ULTSYM.2002.1193449

Repository homepage: https://researchrepository.rmit.edu.au

(c) 2002 IEEE. Personal use of this material is permitted. However, permission to reprint/republish this material for advertising or promotional purposes or for creating new collective works for resale or redistribution to servers or lists, or to reuse any copyrighted component of this work in other works must be obtained from the IEEE.

Downloaded On 2023/04/26 18:03:53 +1000 


\title{
A Layered SAW Device Based on $\mathrm{ZnO} / \mathrm{LiTaO}_{3}$ for Liquid Media Sensing Applications
}

\author{
David A. Powell", Kourosh Kalantar-zadeh, Samuel Ippolito and Wojtek Wlodarski \\ Sensor Technology Group, School of Electrical and Computer Engineering \\ RMIT University, Melbourne, AUSTRALIA. \\ CRC for Microtechnology, Melbourne, AUSTRALIA.
}

\begin{abstract}
Surface Acoustic Wave (SAW) sensors comprising a zinc oxide guiding layer deposited on a $36^{\circ}$-YX lithium tantalate substrate were developed. They were found to have greater mass sensitivity than other $\mathrm{LiTaO}_{3}$ based SAW sensors, such as the $\mathrm{SiO}_{2} / \mathrm{LiTaO}_{3}$ configuration. In this paper, the fabrication of the $\mathrm{ZnO} / \mathrm{LiTaO}_{3}$ sensor is described and micro-characterisation of the deposited films is presented. Sensitivity of these devices to surface mass and dielectric perturbations is then presented, followed by an analysis of temperature stability.
\end{abstract}

\section{INTRODUCTION}

$90^{\circ}$ rotated ST-quartz and $36^{\circ}-\mathrm{YX} \mathrm{LitaO}_{3}$ substrates are the most commonly utilised piezoelectric materials which allow the propagation of shear waves. As a result, they are suitable for use in liquid sensing applications. By depositing a wave guiding layer onto such substrates, mass sensitivity can be increased as the acoustic waves are more confined onto the surface.

Layered SAW sensors for liquid media applications using $\mathrm{SiO}_{2}$ on $90^{\circ}$ rotated $\mathrm{ST}$-quartz have been intensively studied (eg. Kovacs et al [1] and Du et al [2]). $\mathrm{SiO}_{2}$ on $36^{\circ} \mathrm{YX}-\mathrm{LiTaO}_{3}$ layered structure is another SAW structure that offers potential for liquid sensing applications [3, 4]. However, such devices have relatively lower sensitivity than devices based on ST cut quartz.

Adding a piezoelectric guiding layer generally increases the mass sensitivity. It has been shown that replacing the $\mathrm{SiO}_{2}$ layer with $\mathrm{ZnO}$, which is a piezoelectric material, results in considerable improvements in mass sensitivity [5]. In this paper, a $\mathrm{ZnO} / 36^{\circ} \mathrm{YX}-\mathrm{LiTaO}_{3}$ structure is introduced for sensing applications.
Shoji et al. $[6,7]$ showed that deposition of $\mathrm{ZnO}$ layer on $\mathrm{LiNbO}_{3}$ or $\mathrm{LiTaO}_{3}$ results in an improved electromechanical coupling coefficient $\left(\mathrm{K}^{2}\right)$, whilst Lim and Shindo [8] studied the defects in $\mathrm{ZnO}$ deposited on $\mathrm{LiTaO}_{3}$ by electron cyclotron resonanceassisted molecular-beam epitaxy (ECR-assisted MBE). In this paper, it will be shown that the deposition of $\mathrm{ZnO}$ on $\mathrm{LiTaO}_{3}$ can be used in the fabrication of a liquid media sensor with improved mass sensitivity.

\section{SENSOR FABRICATION}

The sensor consisted of a two-port resonator with 38 input and output Inter Digital Transducer (IDT) finger pairs, 160 reflectors on each side, $700 \mu \mathrm{m}$ aperture width and a periodicity of $40 \mu \mathrm{m}$. A 2-port resonator structure was chosen over a delay line as its higher phase slope increases oscillation stability. The IDTs and reflectors were formed by patterning a $300 \mathrm{~nm} \mathrm{Au}$ layer. The Au layer was deposited upon 300nm $\mathrm{Ni} / 300 \mathrm{~nm}$ Ti for improved adhesion to the substrate. Devices were fabricated with $\mathrm{ZnO}$ layer thickness of $1.5 \mu \mathrm{m}$ and $2.6 \mu \mathrm{m}$, deposited by an RF magnetron sputterer. Sputtering gas was $40 \% \mathrm{O}_{2}$ in $\mathrm{Ar}$ at $1 \times 10^{-2}$ Torr, substrate temperature was $260^{\circ} \mathrm{C}$, which resulted in a deposition rate of $\sim 0.4 \mu \mathrm{m} /$ hour. For comparison, transducers with $3 \mu \mathrm{m} \mathrm{SiO}_{2}$ were also fabricated.

\section{MATERIAL ANALYSIS}

$\mathrm{ZnO}$ films were micro-characterised using Scanning Electron Microscopy (SEM) and X-Ray Diffraction (XRD). Figure 1 shows the SEM micrograph of the film at the edge of an IDT finger. It can be seen that grain structure is quite different on the metallised and non-metallised regions. 


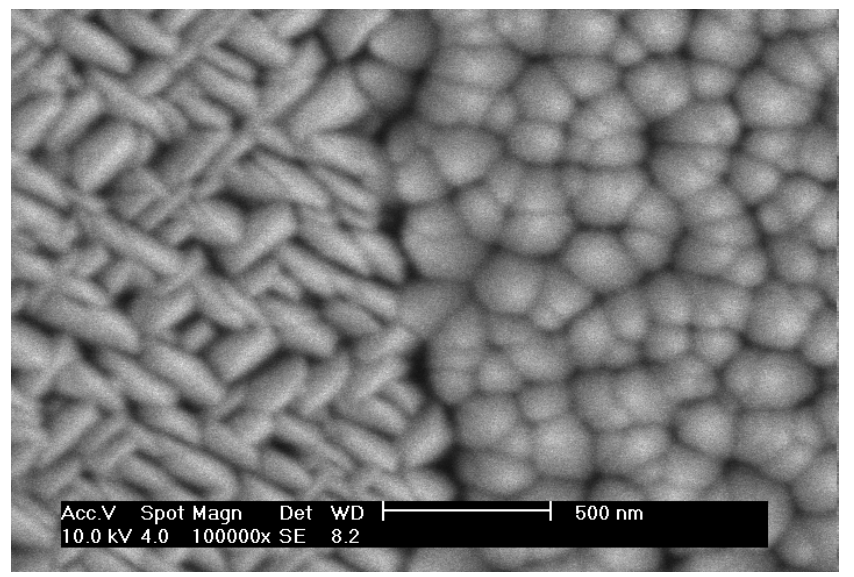

Figure 1: Micrograph $\mathrm{ZnO}$ on $\mathrm{LiTaO}_{3}$ (left) and $\mathrm{Au}$ (right)

It has previously been reported that $\mathrm{ZnO}$ deposited by ECR-assisted MBE grows on $\mathrm{LiTaO}_{3}$ with c-axis alignment parallel to the surface [6]. To confirm that the same relative orientation of thin film and substrate had been achieved with deposition conditions described in section II, a sample with no metal layer was subjected to XRD analysis. The results are presented in Figure 2. The strong (110) peak indicates that the c-axis lies in the plane of the substrate. A smaller (102) peak is also present, but is dominated by the (110) peak. Diffraction angles for crystal orientations have been taken from [6], [10], [11].

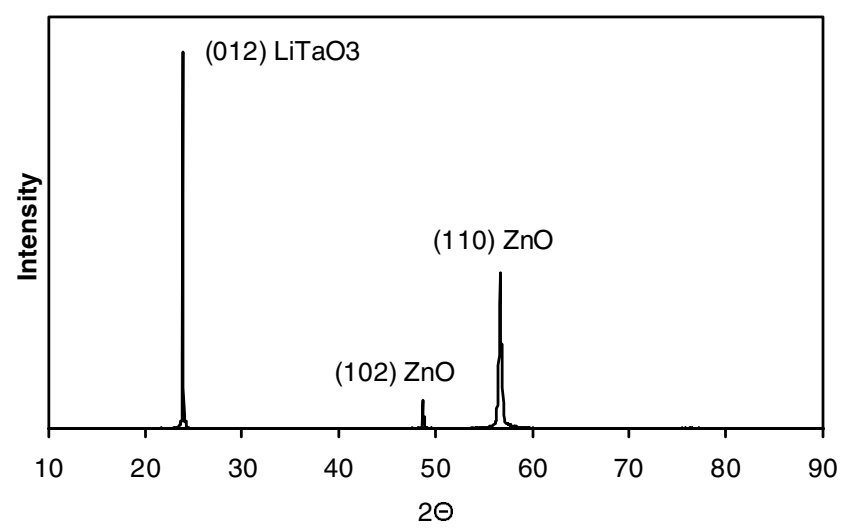

Figure 2: XRD pattern of $\mathrm{ZnO}$ on $\mathrm{LiTaO} 3$

The orientation of $\mathrm{ZnO}$ on $\mathrm{Au}$ under similar sputtering conditions has previously been reported by the authors [2] as showing a strong (002) peak, and a grain formation similar to that on the right side of
Figure 1. This is indicative of strong surface-normal c-axis alignment.

\section{MASS SENSITIVITY ANALYSIS}

To compare the mass sensitivity of the devices with $\mathrm{SiO}_{2}$ and $\mathrm{ZnO}$ layers, a $0.4 \mu \mathrm{m}$ layer of the polymer APC ( Poly(Bisphenol A carbonate) ) was spin coated onto the surface of each SAW device. The frequency shift was measured on a network analyser, and taken as the change at the point of maximum phase slope. From [12], the change in velocity due to mass loading is known to be

$$
\frac{\Delta V}{V}=\frac{V h v_{2}^{2}}{4 P}\left(\rho-\frac{c_{44}}{V^{2}}\right),
$$

where $V$ is the SAW phase velocity, $h$ is the thickness of the perturbing layer, $\rho$ and $c_{44}$ are density and shear stiffness of the film respectively, $P$ is the power flow per unit width, and $v_{2}$ is the particle velocity of the horizontally polarised shear wave. This equation was derived from perturbation theory, using the weak coupling assumption. This is invalid for a strong piezoelectric material such as $\mathrm{LiTaO}_{3}$. However, it is assumed here that the qualitative results are still valid.

Table I: Frequency Response to Polymer Layer

\begin{tabular}{|l|l|}
\hline Device & Frequency Shift \\
\hline $1.5 \mu \mathrm{m} \mathrm{ZnO}$ & $250 \mathrm{kHz}$ \\
\hline $2.6 \mu \mathrm{m} \mathrm{ZnO}$ & $500 \mathrm{kHz}$ \\
\hline $3 \mu \mathrm{m} \mathrm{\textrm {SiO } _ { 2 }}$ & $300 \mathrm{kHz}$ \\
\hline
\end{tabular}

Table I shows that a $2.6 \mathrm{um} \mathrm{ZnO}$ device is approximately 1.6 times as sensitive as a $3 \mu \mathrm{m} \mathrm{SiO}$ device. For comparison, the results of Hermann et al. [3] indicate a sensitivity of $0.5 \times 10^{-8} \mathrm{~m}^{2} \mathrm{~s} / \mathrm{kg} / \mathrm{Hz}$ for a $36^{\circ} \mathrm{YX}-\mathrm{LiTaO}_{3}$ device with periodicity of $40 \mu \mathrm{m}$ and a $3 \mu \mathrm{m} \mathrm{SiO}_{2}$ layer. It was also noted that further sensitivity improvement could be gained by increasing the thickness of the $\mathrm{SiO}_{2}$ layer, however further research needs to be undertaken to determine if this is also the case for a $\mathrm{ZnO}$ layer.

\section{LIQUID SENSITIVITY ANALYSIS}

SAW devices show frequency shift when exposed to different liquids. This is usually due to a combination of viscosity, conductivity and permittivity effects upon the wave propagation. 
To assess the response of the SAW devices in liquid media, they were placed within a $6 \mu$ flow cell. To obtain maximum sensitivity, and to minimise the effects of variable gasket pressure or leakage, the flow cell covered the entire structure, including IDTs and reflectors. This has the disadvantage that input and output impedance will be affected, which has the potential to prevent oscillation [13].

A pump with a flow rate of $250 \mu \mathrm{L} / \mathrm{min}$ supplied DIwater to the surface of the sensor. The sample was injected into a $500 \mu \mathrm{L}$ sample loop and switched into the flow path. Figure 3 shows the response of the three devices when exposed to methanol.

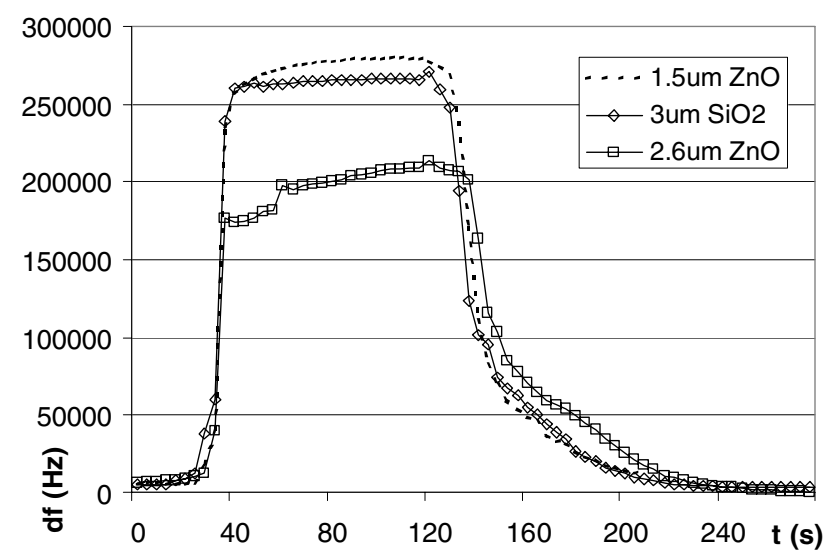

Figure 3: Responses to Methanol

The response is due to the lower dielectric constant and viscosity of methanol compared to water (see Table II). The perturbation relations [12] for velocity shift due to the electrical and mechanical properties of a liquid are respectively

$$
\begin{aligned}
& \frac{\Delta V}{V}=\frac{K^{2}}{2} \frac{\left(\sigma^{\prime} / \omega\right)^{2}+\varepsilon_{0}\left(\varepsilon_{r}{ }^{\prime}-\varepsilon_{r}\right)\left(\varepsilon_{r}{ }^{\prime} \varepsilon_{0}+\varepsilon_{P}^{T}\right)}{\left(\sigma^{\prime} / \omega\right)^{2}+\left(\varepsilon_{r}{ }^{\prime} \varepsilon_{0}+\varepsilon_{P}^{T}\right)^{2}} \\
& \frac{\Delta V}{V}=\frac{V v_{2}{ }^{2}}{4 \omega P}\left(\sqrt{\frac{\omega \eta^{\prime} \rho_{l}{ }^{\prime}}{2}}+\sqrt{\frac{\omega \eta \rho_{l}}{2}}\right),
\end{aligned}
$$

where $\sigma$ is the conductivity, $\varepsilon_{r}$ is the relative permittivity, $\eta$ is the viscosity and $\rho_{l}$ is the density of the liquid. Quantities denoted by ' indicate the perturbing liquid (methanol), while others indicate the water. It is most likely that the dominant effect is the change in dielectric constant, since this sensitivity is proportional to $\mathrm{K}^{2}$. It has been shown that $\mathrm{K}^{2}$ is higher for the $1.5 \mu \mathrm{m} \mathrm{ZnO}$ device than the $2.6 \mu \mathrm{m} \mathrm{ZnO}$ device [7].

Table II: Properties of Methanol and Water

\begin{tabular}{|l|c|c|}
\hline & $\varepsilon_{\mathrm{r}}$ & $\eta(\mathrm{mPa} \mathrm{s})$ \\
\hline Water & 80 & 1 \\
\hline Methanol & 33 & 0.58 \\
\hline
\end{tabular}

This shows that with an appropriate choice of $\mathrm{ZnO}$ layer thickness, it is possible to increase the mass sensitivity, whilst reducing cross-sensitivity due to dielectric constant and viscosity change.

\section{TEMPERATURE COEFFICIENT}

For dispersive SAW devices, including any with layered structure or reflectors, the magnitude of the temperature coefficient of delay (TCD) and temperature coefficient of frequency (TCF) are not identical. Instead, the relationship is [8]

$T C F=-\frac{v_{g}}{V} T C D$,

where $v_{g}$ is the group velocity of the acoustic wave.

To measure TCF, the sensors were placed within an environmental chamber, with the remainder of the oscillator system being kept outside. Figure 4 shows a typical plot of fractional frequency deviation versus temperature for a device with $2.6 \mu \mathrm{m} \mathrm{ZnO}$ layer. It can be seen that it is highly linear over a broad range of frequencies, and gives a TCF of $-40 \mathrm{ppm} / \mathrm{K}$. It was observed that a change in cable lengths between the SAW and amplifier, or an adjustment of the phase shift network, which alters the oscillation frequency, could have a strong impact upon the TCF. Variation was observed over repeated measurement. Since the SAW devices were not hermetically sealed, it is possible that humidity variation caused some additional error.

Table III: TCF of SAW devices

\begin{tabular}{|l|c|c|}
\hline Device & $\begin{array}{l}\text { TCF } \\
(\mathrm{ppm} / \mathrm{K})\end{array}$ & $\begin{array}{l}\text { Variation } \\
(\mathrm{ppm} / \mathrm{K})\end{array}$ \\
\hline $1.5 \mu \mathrm{m} \mathrm{ZnO}$ & -22 & \pm 6 \\
\hline $2.6 \mu \mathrm{m} \mathrm{ZnO}$ & -40 & \pm 4 \\
\hline $3 \mu \mathrm{m} \mathrm{SiO}_{2}$ & -25 & \pm 4 \\
\hline
\end{tabular}




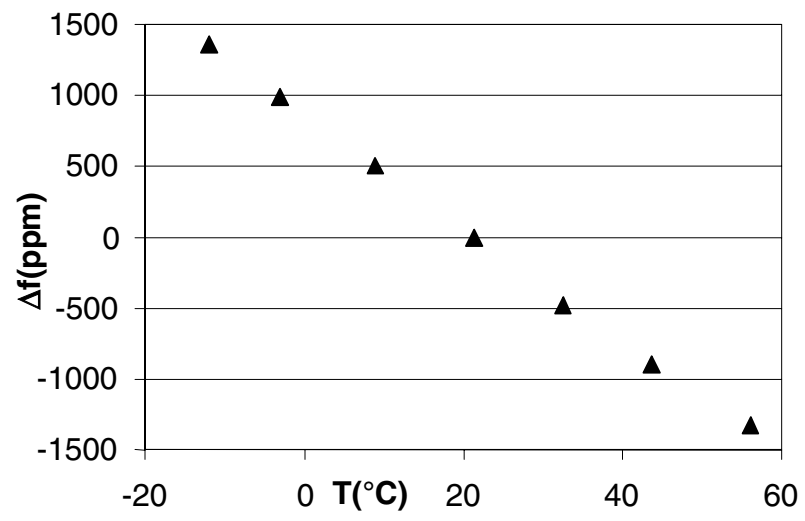

Figure 4: Frequency deviation vs.temperature for $2.6 \mu \mathrm{m}$ $\mathrm{ZnO}$ device.

It can be seen that the TCF of the devices with $\mathrm{ZnO}$ layer is inferior to that of the $\mathrm{SiO}_{2}$ devices. This is due to the opposite signs of the TCD of $\mathrm{SiO}_{2}$ and $36^{\circ}$ $\mathrm{YX}-\mathrm{LiTaO}_{3}$ having a cancelling effect.

\section{CONCLUSION AND FUTURE WORK}

Mass sensitivity of the $36^{\circ} \mathrm{YX}-\mathrm{LiTaO}_{3}$ devices with $1.5 \mu \mathrm{m} \mathrm{ZnO}, 2.6 \mu \mathrm{m} \mathrm{ZnO}$ and $3 \mu \mathrm{m} \mathrm{SiO}{ }_{2}$ layers were compared. It was shown that mass sensitivity of the $2.6 \mu \mathrm{m} \mathrm{ZnO}$ device is 1.6 times that of the $3 \mu \mathrm{m} \mathrm{SiO}$ device, however it suffers from a higher temperature sensitivity. The response to a change in liquid on the surface was measured, and it was found that the $1.5 \mu \mathrm{m} \mathrm{ZnO}$ and $3 \mu \mathrm{m} \mathrm{SiO}_{2}$ devices had a similar response, which was about 1.3 times that of the $2.4 \mu \mathrm{m} \mathrm{ZnO}$ device.

For liquid sensing application, it is proposed to use an $\mathrm{SiO}_{2}$ or polymer protective layer to ensure that $\mathrm{ZnO}$ does not react with any acidic materials within the liquid. Work will be carried out by the authors to model the behaviour of sensors based on $\mathrm{ZnO} / \mathrm{LiTaO}_{3}$, and to apply them to chemical and biochemical sensing applications.

\section{REFERENCES}

[1] G. Kovacs, et al., "Love Waves for (Bio)chemical Sensing in Liquids", in Proc. IEEE Ultrason. Symp., 1992, pp. 281-285.

[2] J. Du, G.L. Harding, A. F. Collings, P.R. Dencher, "An Experimental Study of Love-wave Acoustic Sensors Operating in Liquids", Sens. Actuators A, vol. 60, pp. 54-61, 1997.

[3] F. Herrmann, M. Weihnacht, "Properties of Sensors Based on Shear-Horizontal Surface
Acoustic Waves in $\mathrm{LiTaO}_{3} / \mathrm{SiO}_{2}$ and Quartz/SiO Structures", IEEE Trans. on Ultrason., Ferroelec., and Freq. Contr., vol. 48, no. 1, pp. 268-273, 2001.

[4] J. Freudenberg, M. von Schickfus, S. Hunklinger, "A SAW Immunosensor for Operation in Liquid Using a $\mathrm{SiO}_{2}$ Protective Layer", Sens. Actuators $B$, vol. 76, pp. 147-151, 2001.

[5] K. Kalantar-zadeh, A. Trinchi, W. Wlodarski and A. Holland, "A Novel Love-mode Device Based on a $\mathrm{ZnO} / \mathrm{ST}$-cut Quartz Crystal Structure for Sensing Applications", Sens. Actuators A, vol. 100, pp. 135-143, 2002.

[6] K. Nakamura, T. Shoji and H.B. Kang, "Growth of $\mathrm{ZnO}$ Films on (012) $\mathrm{LitaO}_{3}$ by ECR-MBE and Determination of Their Polarity" in Proc. Int. Symp. App. Ferroelec., pp. 467-470, 2000.

[7] T. Shoji, K. Nakamura and D. Yamazaki, "Propagation Characteristics of the SH-SAW on (110) $\mathrm{ZnO} /(012) \mathrm{LiTaO}_{3}$ " in Proc. IEEE Ultrason. Symp., 2001, pp. 215-219.

[8] S.-H. Lim and A. Shindo, "Defects and Interfaces in an Epitaxial $\mathrm{ZnO} / \mathrm{LiTaO}_{3}$ Heterostructure", Journ. of App. Phys., vol. 88, no 9, pp. 5107-5112, 2000.

[9] B. Jakoby and M. J. Vellekoop, "Reducing the Temperature Sensitivity of Love-Wave Sensors" in Proc. IEEE Ultrason. Symp., 1998, pp. 447450.

[10] Y. Shibata, N. Kuze and M. Matsui, "Piezoelectric $\mathrm{LiNbO}_{3}$ and $\mathrm{LiTaO}_{3}$ Films for SAW Device Applications" in Proc. IEEE Ultrason. Symp., 1996, pp. 247-254.

[11]X. T. Zhang et al, "Temperature Dependence of Excitonic Luminescence from Nanocrystalline ZnO films", Journal of Luminescence, vol. 99, pp. 149-154, 2002.

[12] J. Kondoh, K. Saito, S. Shiokawa and H. Suzuki, "Simultaneous Measurements of Liquid Properties Using Multichannel Shear Horizontal Surface Acoustic Wave Microsensor", Jpn. J. Appl. Phys., vol. 35, Part 1, No 5B, pp. 30933096, 1996.

[13] B. Jakoby and M. J. Vellekoop, "Analysis and Optimization of Love Wave Liquid Sensors", IEEE Trans. on Ultrason., Ferroelec., and Freq. Contr., vol. 45, no. 5, pp. 1293-1302, 1998.

\footnotetext{
* Corresponding author: david.powell@ieee.org
} 